\title{
Special Issue: Traditional Chinese Medicine
}

Traditional Chinese Medicine (TCM) is going to become globally practised. In order to be accepted by the conventional medical system, it will be necessary to prove efficacy, safety, and quality. The special challenges in the scientific evaluation of TCM are its specific medical theory, which is completely different from Western pharmacological systems, and the application of its complex formulas. Therefore, a new approach is needed, which considers the holistic and personalized character of TCM. Systems biology and metabolomics are probably most adequate to match this aspect both in the diagnostic field and in the elucidation of the mechanisms of action.

A lot of research is currently going on in all the fields necessary for evaluation and modernization of TCM. Therefore, Planta Medica has decided to publish a special issue on TCM research. As the editors of this special issue, we are very happy that so many renowned scientists have accepted our invitation to write a review on their particular field of expertise. By this, we could compile a very interesting overview on the most prominent fields of TCM research, ranging from the application of Good Agricultural Practice and cultivation of medicinal plants, processing and quality control using chemometric assessment of Chinese materia medica, via pharmacologic research, systems biology in diagnostics, and toxicological evaluation to clinical studies. Also the important aspect of processing is covered.

The editors are grateful to the Editorial Board members of Planta Medica who have accepted to publish a special issue on TCM research, to Thieme Publishers, in particular to Daniel Bauer, for the support in bringing the manuscripts to the printer in time, and, last but not least, to all authors who have spent their precious time to prepare the reviews.

Rudolf Bauer and Kelvin Chan
Bibliography

Dol http://dx.doi.org/ 10.1055/s-0030-1250543

Planta Med 2010; 76: 1947

(c) Georg Thieme Verlag KG

Stuttgart · New York .

ISSN 0032-0943

Correspondence

Univ.-Prof. Dr. Rudolf Bauer

Institute of Pharmaceutical

Sciences

Department of Pharmacognosy

Karl-Franzens-Universitaet Graz

Universitaetsplatz 4/I

8010 Graz

Austria

Phone: + 433163808700

Fax: + 433163809860

Rudolf.Bauer@uni-graz.at 